\title{
Significant Psychiatric Recommendations Irresponsibly Made
}

\section{Review of Allan V. Horwitz and Jerome C. Wakefield. The loss of sadness: How psychiatry transformed normal sorrow into depressive disorder, (New York: Oxford University Press, Inc., 2007), xiii+225 pp. \$29.95 (hardcover).}

\section{Richard E. Vatz}

Correction: Horowitz should be spelled Horwitz in the article title and throughout the article.

The online version of the original article can be found at http://dx.doi.org/10.1007/s12144-007-9010-x of the article with published errors.

R. E. Vatz $(\bowtie)$

Department of Mass Communication and Communication Studies, Towson University, Towson, MD 21204-7097, USA

e-mail: rvatz@towson.edu 